6. Success and wealth are bad ethically only insofar as they are temptations to idleness.

7. Time is money.

8. He who will not work shall not eat.

. We are each assigned to a position and it is our duty to persevere in that position.

10. Wealth and success do not exempt anyone from the command to labor.

1. We must acquire all we can and save all we can

12. The acquisition of wealth is bad only when it is with the purof later living merrily and without care.

*on all of the items of this scale "strongly agree" is the strongest protestant ethic response.

14 Goldman-Eisler, "Breastfeeding and Character Formation," in C. Kluckhohn, et al. Personality in Nature, Society, and Culture (New York: Knopf 1953) pp. 146-184.

\section{THE IMPLICATIONS OF DURKHEIM'S}

\section{PHILOSOPHY OF SCIENCE}

\author{
Judith Willer \\ University of Kansas
}

\section{Durkheim and His Critics}

Reading Durkheim's critics leads one to conclude that either Durkheim was very confused or they are. Between them there is certainly no conscience collective. Some have claimed he was "conservative"1 while others deny it; 2 his logic has been described as "fallacious" 3 and "incisive" 4 ; he is a "moral philosopher"5 to one critic and a "great empirical scientist" 6 according to another; his use of "conscience collective" is praised by one writer 7 and described as "deplorable" 8 by another; he has been characterized as "anti-individualistic" 9 by one critic while another has denied it. 10

Perhaps the contradictory interpretations result from a real inconsistency in his work. Possibly he cannot be understood because his work is "out of line with twentieth-century thought."11 Such explanations, however, are excessively superficial. What is the basis for the claim that Durkheim is inconsistent? It seems plausible that his thought is more complex than is typically realized by scholars. searching it for simple logical continuities or discontinuities. Perhaps he merely appears inconsistent because he has been apprehended from diverse points of view or from a single point of view foreign to his own thought. Many of his critics have ignored the possibility that Durkheim's ideas were subject to development (as might surely be expected of any competent scholar) and that his writings could not thus be expected to agree on every point.

Moreover, Durkheim's ideas should not be loosely compared with "twentieth-century thought." Such a comparison both takes Durkheim out of his temporal context and implies that modern methods are necessarily "better". If Durkheim had a goal different from that of modern sociology his method could be expected to be different. Different scientific ideas and goals are not necessarily wrong ideas and goals - this assumption would lead to a science both static and 
conservative. Or has sociology already become "positive" as Saint-Simon believed it would?

\section{The Content of Sociological Knowledge}

Much sociology today consists of gathering psychological data. Questionnaires are commonplace, and individual opinions frequently form the basis for simple generalizations about society. "Status" is regarded as a sociological term, but is often measured by resorting to individual opinions.

Durkheim did not believe that such studies form the proper content of sociological knowledge, particularly as ends-in-themselves. "A discipline may be called a science only if it has a definite field to explore."12 He felt that it is important to segregate sociology from other fields of study, particularly from psychology and philosophy which he viewed as threats to the development of sociology as an independent science. The claim that Durkheim was "anti-individualistic" fails to take this point into account. He was not anti-individualistic but pro-sociology, and these two positions are not identical. Sociology must have a clear field of endeavor unhampered by a psychological point of view and metaphysical speculation. Thus the study of individual actions is not opposed to the study of the constraints of society - this does not become a controversy - the former is merely the domain of psychology and the latter that of sociology. Free will vs. determinism is likewise not a sociological problem but instead a purely metaphysical (and philosophical) problem and has no place in the study of society. 13

Durkheim maintained that the individual is the "basic element of human groups;"14 but "For sociology, properly speaking, to exist, there must occur in every society phenomena of which this society is the specific cause, phenomena which would not exist if this society did not exist and which are what they are only because this society is constituted the way it is."15

Durkheim's ideas can be easily misunderstood if the meaning of the term "society" is taken from context and assumed to be an empirically defined area.

When Durkheim wrote of "society" he was not considering it in the modern sociological sense. It did not occur to him to delineate the "boundaries" of society. The specification of boundaries for society is an "empiricist" concern, the concern of someone who believes that he can go out into the real world and draw lines around a section of it which he can then study as a single unit or "society." Durkheim was not that naive. Society for Durkheim was that domain in which social phenomena occur. It is thus theoretically defined according to the phenomena the sociologist is presently studying. He asks himself under what conditions he can expect to find a certain phenomenon and those conditions define the domain of society. Society thus is not an empirical area with physical boundaries, but a theoretical domain with theoretically hypothesized conditions under which it can be empirically studied.

Durkheim was no more conservative that he was anti-individualistic He did not claim that the individual must submit to the group and thus resist change. The group has been designated as the proper domain of sociological study, and the reasons for not studying individuals in order to understand the group are not moral, but methodological: "The group thinks, feels, and acts quite differently from the way in which its members would were they isolated. If, then, we begin with the individual, we shall be able to understand nothing that takes place in the group."16 This is not to say that every individual must submit to the group but that group phenomena should be studied as they are different from individual phenomena. Nor does this mean that we should proceed to put aside all data relating to individuals. Durkheim was concerned at this point with theoretical analysis (not data), and the starting point for sociology is thus the development of theoretical concepts for the phenomena of group activity. The conceptualization of a "conscience collective" provided such a beginning for Durkheim in his study of society.

As characteristics of individuals may be units of analysis for the psychologist, the conscience collective was a distinctive feature of sociological analysis. It was not, as has sometimes been claimed, a sort of conscience that dictated the morality of the group claimed, a sort Parsons described it, "patterns of normative culture that are institutionalized in the social setting .... in the personalities of its individual members."17 Parsons' "redefinition in personalities of its individual members." 7 Parsons' "redefinition in modern terms" reduces con science collective to an empirical category. Conscience collective does not consist of a common culture or values shared by individuals. These are defined by their empirical existence, while conscience collective is a theoretical concept, a tool for analysis, a point of view from which to apprehend social phenomena and thus be able to understand it as more than a set of unrelated empirical facts. According to Durkheim, "the psychological factor is too general to predetermine the course of social phenomena. Since it does not call for one social form rather than another, it cannot explain any of them."18 The assumption of Durkheim's approach is that individual facts do not order themselves. Thus they may be used as indicators of one or another type of conscience collective but are never equivalent to it.

Because of his use of the conscience collective, Durkheim is commonly regarded as an early "functionalist" - clearly Parsons regards himself as part of Durkheim's tradition. Although Durkheim did frequently use the term "function", he did not think the procedure of 
studying social elements in relation to their consequences was a wise procedure. He wrote that "the method of explanation generally followed by sociologists is essentially psychological.... In fact, if followed by sociologists is essentially psychological. . . In tain certain ends, these ends can only be individual, for only individuals could have existed before society."19

The conscience collective consequently should not be regarded as embodying some sort of purpose or end. Probably Durkheim was actually criticizing the procedures of some of his contemporaries, but it actuatly cres sems and Merton. For sometimes seems as if he were anticipating Parsons and Merton. For example: "We use the word 'function,' in preference to 'end' or 'purpose,' precisely because social phenomena do not generally exist for the useful results they produce. ... All these questions of intention are too subjective to allow of scientific treatment."20 It is certainly very easy to fall into the tendency to think of Durkheim's conscience collective in terms of the modern notion of "function" (as opposed to "dysfunction") but this is clearly a mistake.

The apparent ambiguity of the conscience collective may, on the other hand, result from the fact that it was never defined in terms of genus proximum and differentia specifica. But, as Carl Hempel has genus proximum and not all scientific terms may be defined in this way. 21 Furthermore, conscience collective, as a scientific concept, may not be defined by any of the conventional or textbook logic modes of definition. It (like numerous other scientific terms such as "elastic," "fissionable," "bureaucratic," and so forth) is a "dispositional" term which gains its meaning from two sources: (1) its empirical indicators, and $(2)$ its use in conjunction with other theoretical concepts. Since it is always possible to locate further indicators for a dispositional term and always possible to construct further connections with othe theoretical terms, its meaning can never be fully or finally determined.

The recognition of the special nature of dispositional terms is a relatively recent event in the philosophy of social science. 22 Consequently Durkheim's correct use of dispositional concepts more than 36 quently Durkheim's correct use of dispositional concepts mor so horrible that conscience collective was never fully defined - it could not be, for it was not an empirical category. Instead, as a theoretical concept, it was indicated by certain empirical phenomena. "Constraint" was, for example, described as a characteristic of the conscience collective which influenced the "social facts," but it was intended neither as an explanation of social phenomena nor the only possible indicator of conscience collective. But he wrote that he was instead interested in indicating "by what external signs it is possible to recognize the facts in order that the student may know how to detect them and that he may not confuse them with others. ... Q Quite obviously, the social fact may be characterized in several ways, and there is no reason why any one certain distinctive characteristic should be attached to it oftener than any other. It is only important to choose that characteristic which appears the best for one's purpose; and it is even quite possible to use, concurrently, several criteria, according to the circumstances."23

"Institutions" are other such empirical indicators of the conscience collective:

'It has been pointed out that the word 'institution' well expresses this special mode of reality, provided that the ordinary significance of it be slightly extended. One can, indeed, without distorting the meaning of this expression, designate as 'institutions' all the beliefs and all the modes of conduct instituted by the collectivity. Sociology can then be defined as the science of institutions, of their genesis and of their functioning." 24

Not only is sociology the study of institutions, but it should assist in the diagnosis of the social organism to determine whether it is sick or healthy. "We shall call 'normal' these social conditions that are the most generally distributed and the others 'morbid' or 'pathological." "25 Perhaps it is because of this unfortunate aspect of Durkheim's thought that some scholars have been led to believe that he was a "moral philosopher"; but Durkheim would not agree. He believed that the diagnosis of societies was scientific rather than moral. He did not appear to realize that the belief that solidarity was "normal" was itself a moral judgment. Nevertheless, since Durkheim was not preaching morality or seeking to justify a morality, his studies do not suffer from this type of "functionalism".

\section{Durkheim's Method}

Sociology should proceed by the scientific method. Its subject matter is "institutions." Durkheim's commitment was an unusual one by today's standards, for his works reflect a continual attempt to apply scientific methods to sociology. The common approach in sociology today is to assume that any approach to the subject matter is correct and scientific as long as we use the proper statistical techniques. Durkheim was aware that the scientific method was much more than this, that statistical data are not science, and that an explanation or theory involving relationships between social phenomena was necessary. His elaboration and codification of his method run throughout his works, and the reader is always aware that Durkheim is struggling with the problem of knowledge in social science.

The exposition of his method begins in The Division of Labor in Society: "Moral facts are phenomena like others; they consist of rules of action recognizable by certain distinctive characteristics. It must, then, be possible to observe them, describe them, classify them, and look for the laws explaining them."26 In this book Durkheim was 
seeking the causes of certain types of solidarity in society: "But we can know causes scientifically only by the effects that they produce, and in order to determine their nature, science chooses from these effects only the most objective and most easily measurable. Science studies heat through the variations in volume which changes in temperature produce in bodies, electricity through its physico-chemical effects, force through movement. Why should social solidarity be any different?" 27 This is clearly not a plea for our modern type of functionalism - it is a clear statement of Durkheim's conscious understanding of the use of dispositional terms in the physical sciences.

Furthermore: "Since law reproduces the principal forms of social solidarity, we have only to classify the different types of law to find therefrom the different types of social solidarity which correspond to it. It is now probable that there is a type which symbolizes this specia solidarity of which the division of labor is the cause. That found, it will suffice, in order to measure the part of the division of labor, to compare the number of judicial rules which express it to the total volume of law."28

At this point Durkheim's method consists of: (1) hypothesizing a connection between a social phenomenon to be examined (division of labor) and an explanatory concept (solidarity), (2) choosing objective and measurable empirical indicators (types of law) for that concept, (3) classifying these indicators by the degree to which they are of a specific type, and (4) relating the types of the concepts thus measured to the phenomena he wishes to explain (division of labor)

It is sometimes assumed from statements such as "the essential properties of a thing are those in which one observes universally wherever that thing exists and which pertain to it alone,"29 that Durkheim believed that sociology studies only universal phenomena which can be found throughout social life. On the contrary, it is not the universal presence of phenomena which is crucial to Durkheim but the universal connection of indicators to their concepts which is seen as essential for their definition.

Much stress is put on Durkheim's description of "social facts" which should be treated as "things." It appears that some of the confusion arising from this is to be found in English translations which render "faits" as "facts". It is the obvious translation if one considers the similarity of the words, but the word can legitimately be translated as "acts" - a much more common meaning of the word in French. Thus social acts are empirical things which are dependent on the "institutions" of society. Theoretically and conceptually social acts depend on the conscience collective. This conception makes considerably more sense in the contexts in which the term was used.

Reading into The Rules of the Sociological Method "act" instead of "fact" leads to a startling new viewpoint toward Durkheim's thought.
Consider the new and more dynamic message that the following translation produces when "acts" are substituted for "facts": " $A$ social act is every way of action, fixed or not, capable of exercising on the individual an external constraint, or again, every way of acting which is general throughout a given society, while at the same time existing in its own right independent of its individual manifestations." 30 Here Durkheim was concerned with distinguishing the special types of acts which may be considered "social." They are conceptually related to the conscience collective because that is the defining element which makes them specifically sociological. They must be considered as "things" because that is how the scientist proceeds - he considers things objectively. Objectivity is the quality of "thingness." Thus Durkheim's commentary on the way in which his concept has been "misinter preted" begins to make sense:

"We assert not that social acts are material things but that they are things by the same right as material things, although they differ from them in type. . . . To treat acts of a certain order as things is not, then to place them in a certain category of reality but to assume a certain mental attitude toward them as the principle that when approaching their study we are absolutely ignorant of their nature, and that their characteristic properties, like the unknown causes on which they depend, cannot be discovered by even the most careful introspection."31

This alternative translation also clarifies Durkheim's rejection of universality as a requirement of sociological study:

"A thought which we find in every individual consciousness, movement repeated by all individuals, is not therby a social act."32 It follows that it is not generalization about the universal, but the deliberate limitation of the area of investigation by the investigator that allows us to study sociological phenomena: "the subject matter of every sociological study should comprise a group of phenomena defined in advance by certain common external characteristics, and all phenomena so defined should be included within this group."33

Here the similarity of Durkheim's "social act" to Weber's "social action" may be recognized. By "common external characteristics" Durkheim clearly did not mean similar manifestations but fixed indicators. To take an example from Weber, the social actions of both those characterized by the protestant ethic and those characterized by the traditional ethic may be indicated by "common external characteristics," specifically the relative accumulation of capital. Taking an example from Durkheim, the social acts of those who are and are not egoistic may be characterized in an aggregate by differential rates of suicide. It is through common characterization that individual cases may be differentiated. 
Finally Durkheim's specific use of theoretical concepts is notable. He realized that concepts are necessary elements of science and that science consists of more than simple generalizing:

"If concepts were only general ideas, they would not enrich knowledge a great deal, for, as we have already pointed out, the general contains nothing more than the particular. ... Thinking by concepts is not merely seeking reality on its most general side, but it is projecting a light upon the sensation which illuminates it, penetrates it, and transforms it."34

Modern sociologists do not appear to find fault with sweeping generalization - often it becomes a "method" to be religiously adhered to. Durkheim showed no such faith in his method. He pointed out that "science rests upon opinions." 35 He wished to present a method that would be useful in generating scientific laws about society. The test of opinion has rejected his method in the sense that it is neither understood not used. The question of whether his own use of his method was successful in achieving his goals remains disputed.

\section{Suicide as a Social Act}

Durkheim's study of suicide has been regarded as the classic example of an empirical study in sociology. It is thus differentiated from the earlier studies by Plato, Aristotle, Rousseau and others by its empirical approach. But it is not Durkheim's empiricism that makes this study a classic - especially since Durkheim regarded pure empiricism as a dead end. Empiricism, according to Durkheim, is individualized, and, being so, it results in irrationalism and cannot provide concepts for science. The "a priorists", on the contrary, assume that the mind has the power of transcending. experience. These two conceptions are equally futile: "If reason is only a form of individual experience, it no longer exists. On the other hand, if the powers which it has are recognized but not accounted for, it seems to be set outside the confines of nature and science."36

Durkheim's method is an attempt to be scientific by combining the empirical with the conceptual. Suicide will be examined here, as an example of the application of this method.

The measurement of concepts by empirical indicators is an integral part of their formulation. Durkheim discussed four possible types of suicide: egoistic, altruistic, anomic, and fatalistic.

Since Durkheim's types of suicide are often confused, perhaps it will be useful to place them in the context of his other studies. Table 1 relates altruistic and egoistic suicide to the particular types of conscience collective that are found in mechanical and organic societies, respectively.
Table 1. Suicide Based on Conscience Collective

\begin{tabular}{clc} 
Type of Conscience Collective & Type of Society & Type of Suicide \\
\hline "socialism" & $\begin{array}{l}\text { mechanical } \\
\text { organic }\end{array}$ & $\begin{array}{l}\text { altruistic } \\
\text { egoistic }\end{array}$
\end{tabular}

The connection made here is not obvious from Durkheim's discussion of suicide, but has been made here to clarify more specifically the place of the study of suicide in his thought. Together with Table 2 , it seems to point out the distinction between anomic and egoistic suicide which tends to be confused in his work. Table 2 relates fatalistic and anomic suicide to the types of solidarity found in mechanical and organic societies, respectively.

Table 2. Suicide Based on Solidarity

\begin{tabular}{ccc} 
Type of Solidarity & Type of Society & Type of Suicide \\
\hline $\begin{array}{c}\text { likeness } \\
\text { difference }\end{array}$ & $\begin{array}{c}\text { mechanical } \\
\text { organic }\end{array}$ & $\begin{array}{c}\text { fatalistic } \\
\text { anomic }\end{array}$
\end{tabular}

Perhaps it could be claimed here that Durkheim's meanings have been distorted, but this seems doubtful. In fact, this sort of conceptual analysis is a distinctive feature of all of Durkheim's work. It is not likely that his hypothesized types of suicide would be inconsistent with the rest of his theory and method. It is conceptual analysis that rescues Durkheim from pure empiricism. The concept of suicide as a social act is related theoretically to the concepts of mechanical and organic society through the concepts of solidarity and conscience collective. Does this conceptualization through theoretical connection provide the basis for the empirical consideration of suicide as a social act? In other words, can the empirical relations of suicide with other social phenomena be explained by the proposed theory?

The social act of suicide is considered in relation to the hypothesized social conditions which, in turn, are measured or indicated empirically. The logic of this procedure may be diagrammed as follows:

Social Level: Explanatory Mechanism

lack of integration Psychological level:

Social level:

(Measured)

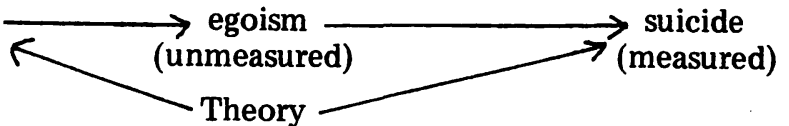


One of the indicators Durkheim used for "lack of integration" or "individualism" was the traditionalistic aspect of religion. The more traditionalistic (having less room for individual judgment) were expected to have the lowest suicide rates. The least traditionalistic were expected to have the highest (egoistic) suicide rates. He could thus relate the three major religions of Europe, Protestant, Catholic and Jewish, according to the traditionalistic criterion. He then related membership in these religious groups to suicide rates and found, as expected, that Protestants exhibited a higher suicide rate, the Catholic rate was lower, and the suicide rate for Jews somewhat lower than for Catholics.

Durkheim also related his theoretical concept to several other empirical indicators, lending additional support to his hypothesis. $\mathrm{He}$ measured only two of the concepts of his theory, not egoism. Egoism here is merely a psychological explanatory device that connects the terms of his theory; however, if the theory is found to hold, then egoism could be used as a possible explanation of individual cases.

This type of explanation is rare in modern sociology (although it was also the method Weber used to analyze the rise of capitalism). It cannot be understood from the prevalent points of view of modern sociology. Most critical analyses of Durkheim's method have this fault. The criticism by Jack Douglas is probably the most careful and comprehensive of these and will thus be used here as an explanatory example.

Douglas very perceptively notices the difference between Durkheim's theoretical and explanatory levels of meaning, but thought that this was somehow a fault of Durkheim's method: "the meanings imputed to suicide independent of concrete situations in which the communicator is involved are different from the meanings imputed to concrete situations in which the communicator is involved. In general terms this means that the situated meanings are significantly different from the abstract meanings."37

Douglas believes this element of Durkheim's procedure to be faulty for two reasons:

1. "It is not possible to predict or explain specific types of social events, such as suicide, in terms of abstract social meanings, such as abstract values against suicide. This generalization is a denial of the fundamental assumption of most general theories of today."38 Here Douglas, in accordance with the "fundamental assumptions" of modern sociological theories, equates Durkheim's "abstract social meanings" with "generalization." As has been seen, this is inconsistent with Durkheim's method - neither his theory nor its explanation are intended to "duplicate" reality, for generalization, according to Durkheim, adds nothing to knowledge. His explanation is conceptually different from the empirical events to which it refers. He did not intend to predict from his imputed abstract social meanings - they are merely explanatory tools. Prediction is involved at the level labeled "Theory" in the diagram and is not a consequence of any single concept. Thus the measurement of integration (through empirical indicators) should enable the investigator to predict the suicide rate (directly measurable) which may be explained as a manifestation of egoism. Furthermore terms such as "egoism" and "fatalism" are not empirical categories (or generalizations) but logical constructs of dispositional type.

2. "It is not possible to study situated social meanings (e.g., of suicide) ... by any means that involve abstracting the communicators from concrete instances of the social action in which they are involved."39 Why not? Has Durkheim done the impossible? This assumption is based on the viewpoint that all scientific abstractions are merely abstractions from concrete situations. On the contrary, the application of reason to scientific explanation is usually recognized in other sciences as a valuable technique. Douglas' criticism here is similar to Dalton's rejection of the molecular hypothesis, seemingly based on the assumption that phenomena which are not directly observed do not exist. But inferences based on molecular theory were quite useful, thus legitimizing the conceptualization of molecular structure. Interestingly later developments in measurement allowed more direct apprehension of molecular structure. Given some logically equivalent measurement development, there is some reason to believe that concepts such as "egoism" may be more directly apprehended in the future.

It is true that Durkheim does not use psychological data to establish his theory - it is also true that he occasionally uses individual cases as examples. This is perfectly consistent with his method. Psychologica data cannot lead to sociological explanations; however, once the sociological explanation has been hypothesized, individual cases may be explained by it. Suicide rates are predicted by the theory, and individual cases are to be understood in terms of the explanatory mechanism (e.g., egoism). Paradoxically, the various psychological cases that Douglas cites in his book could easily be explained as manifestations of Durkheim's types of suicide. 40

Douglas maintains that "Durkheim bends the data to fit his preconceived theory." 41 He attempts to demonstrate that this is so by pointing out that Durkheim's ideas on suicide can be found in some of the works of his contemporaries. It is true that Durkheim was influenced by a knowledge of other works on suicide. It is usually expected of most students of scientific phenomena that they be acquainted with the other work in the area. Durkheim, in fact, proposed his theory as a result of such study which led him to recognize the futility of other explanations. It is clear that such study had an important influence on his work: his theory was partly a result of it, and his method was influenced by the mistakes he thought he found there. Of particular interest is the work of Marselli who relates 
psychological, physical, cosmic, racial conditions to the incidence of suicide without offering any theoretical explanation other than the untempered passions of individuals in the struggle for existence. 42 This explanation may well have led to Durkheim's concept of "egoism,"43 but it is hardly an adequate explanation of the whole of Durkheim's theoretical meaning. Such a purely psychological explanation contributes nothing to the prediction of the incidence of suicide which, according to Durkheim, must be measured in social terms. Marselli himself recognized the futility of prediction from a psychological explanation, so he explained that suicide rates were merely a manifestation of the "law of averages." 44 Durkheim criticized the notion of averages as an explanation of suicide since the average man does not commit suicide. 45 If it is meant that there is a probability that a certain number of individuals will kill themselves during a year, this still tells us nothing of the average inclination to do so. 46 The "law of averages" thus is not an explanation of anything.

The criticism that Durkheim developed his ideas from reading other works on suicide appears more complimentary than otherwise. If Douglas' point was that it was somehow wrong of Durkheim to have a theory before he tested it, it may be true that this violates modern sociological assumptions; but Durkheim's method is consistent with the so-called "scientific method" discussed by philosophers of science. Douglas argues "Besides being out of line with twentieth-century scientific thought, Durkheim's general theory has the great fault of being adjustable in such a way as to be irrefutable."47 Is this a fault? The most useful theories in physical science are precisely those which may be extended or revised to include new data.

\section{The Road Ahead}

If we agree with Durkheim that sociology should be scientific, and if we agree that it is possible to proceed by means of a "scientific method" then it is difficult to reject the methods Durkheim used. His belief that sociology should study the "social" is certainly not revolutionary, nor is his notion that science consists of more than pure empiricism or "apriorism."

The basic problem in understanding Durkheim's thought is that we tend to approach him with our own preconceptions about procedure and criticize him whenever he veers from the path which we continue to trample firmly beneath us, unable to follow any other. We cannot understand his work by simply comparing him with his contemporaries - he pioneered a path of his own, the intricacies of which are still being analyzed by philosophers of science. He cannot be understood in terms of the sociology of today - its "assumptions" block off entrance to a new level of understanding. He can only be understood in the terms of modern philosophy of science. There we find support for his method, and there we also find the basis for questioning the assumptions of sociology which we have held so long.

The legitimization of Durkheim's method depends on his own success in using it, since it is not used today. It must be understood in his own terms. The value of his study of suicide must be determined in relation to the strength of the relationships tested. A refutation of his theory would require retesting in order to determine whether the theory holds in other cases. Even then, perhaps a rejection of the theory would be less advisable than a revision.

My own criticism of Durkheim's use of his method in Suicide would be quite different from Douglas'. After specifying the importance of theoretical conceptualization, it appeared to me that Durkheim did not carry it far enough. He left the distinction between egoism and anomie rather fuzzy. This is not because they are empirically mixed, although they may be, but because his theoretical formulation of his concepts was inadequate. He has made this point himself: "Sociologists so commonly use terms without defining them, neither establishing nor methodically circumscribing the range of things they intend to discuss, that they constantly but unconsciously allow a given expression to be extended from the concept originally or apparently envisaged by it to other more or less kindred ideas."48 In this instance, Durkheim failed to rigorously attend to his own advice.

\section{FOOTNOTES}

1 See Lewis A. Coser, "Durkheim's Conservatism and Its Implications for His Sociological Theory," in Kurt H. Wolff, ed., Essays on Sociology and Philosophy, New York: Harper and Row, 1964, p. 215.

2 See Joseph Neyer, "Individualism and Socialism in Durkheim," in Essays, op. cit., p. 32

3 See R. Needham, "Introduction" to Durkheim and Mauss' Primitive Classification, trans. R. Needham, Chicago: University' of Chicago Press, 1967, p. xxix.

4 See George Simpson's "Preface to the Translation" of Durkheim's The Division of Labor in Society, Glencoe: The Free Press, 1964 p. $\mathbf{x}$.

5 See Robert A. Nisbet, Emile Durkheim, Englewood Cliffs: Prentice Hall, 1965, p. ix. 
6 See Talcott Parsons, The Structure of Social Action New York: The Free Press, 1968, Vol. I, p. 302.

7 See Parsons, "The Integration of Social Systems," in Essays, op. cit., p. 150

8 See George E. G. Catlin's "Introduction to the Translation" of The Rules of Sociological Method, New York: The Free Press, 1964, p. xiv.

9 See Robert K. Merton, "Durkheim's Division of Labor in Society," in Emile Durkheim, op. cit., p. 105.

10 See Joseph Neyer, op. cit., p. 36.

11 This criticism is from Jack Douglas, The Social Meanings of Suicide, Princeton: Princeton University Press, 1967, p. 75.

12 Emile Durkheim, Montesquieu and Rousseau, Ann Arbor, Michigan: The University of Michigan Press, 1960, p. 3.

13 See Durkheim, Rules, op. cit., p. 141.

14 See Essays, op. cit., p. 325.

15 Ibid., p. 363.

16 Durkheim, Rules, op. cit., p. 104.

17 Parsons, Sociological Theory and Modern Society, New York: The Free Press, 1967, pp. 7-8.

18 Durkheim, Rules, op. cit., p. 108.

19 Ibid., p. 97.

20 Ibid., p. 95

21 See Carl Hempel, Fundamentals of Concept Formation in Empirical Science. Chicago: University of Chicago Press, 1952, p. 5.

22 For the first discussion of disposition terms see Rudolf Carnap, "Testability and Meaning," Philosophy of Science, III (1936), pp. 419-71, and VI (1937), pp. 1-40.

23 Durkheim, Rules, op. cit., pp. liii-liv.
24 Ibid., p. lvi.

25 Ibid., p. 55.

26 Durkheim, Division of Labor, op. cit., p. 32.

27 Ibid., p. 66

28 Ibid., p. 68.

29 Ibid., p. 70.

30 Durkheim, Rules, op. cit., p. 13.

31 Ibid., p. xliii.

32 Ibid., p. 6.

33 Ibid., p. 35.

34 Emile Durkheim, The Elementary Forms of the Religious Life trans. J. W. Swain, New York: Collier, 1961, p. 483-484.

35 Ibid., p. 483.

36 Ibid., p. 28.

37 Douglas, op. cit., p. 339.

38 Ibid., p. 339.

39 Ibid., p. 339.

40 Ibid., pp. 277-278.

41 Ibid., p. 25.

42 See Henry Marselli, Suicide: An Essay on Comparative Moral Statistics, New York: D. Appleton and Co., 1882.

43 In fact, Marselli used the term. See Ibid., p. 297.

44 Ibid., p. 271

45 See Emile Durkheim, Suicide, p. 302 
46 Ibid., p. 304.

47 Douglas, op. cit., p. 75.

48 Durkheim, Suicide, op. cit., p. 124. 